\title{
Application of Replica Ornstein-Zernike equations in studies of the adsorption of electrolyte mixtures in disordered matrices of charged particles*
}

\author{
M. Lukšič ${ }^{1}$, G. Trefalt ${ }^{2}$, B. Hribar-Lee ${ }^{1}$ \\ ${ }^{1}$ Faculty of Chemistry and Chemical Technology, University of Ljubljana, \\ 5 Aškerčeva Str., SI-1000 Ljubljana, Slovenia \\ 2 Jožef Stefan Institute, Jamova 39, SI-1000 Ljubljana, Slovenia
}

Received June 9, 2009, in final form June 19, 2009

\begin{abstract}
The Replica Ornstein-Zernike (ROZ) equations were used to study the adsorption of ions from electrolyte mixtures. The adsorbent was represented as a quenched primitive model $+1:-1$ size symmetric electrolyte, while the mobile particles were ions differing in charge and/or size. The ROZ equations in hypernetted-chain (HNC) approximation were tested against new Monte Carlo results in the grand canonical ensemble; good agreement between the two methods was obtained. The ROZ/HNC theory was then used to study the exclusion coefficients as a function of size and/or charge asymmetry of the annealed ions.
\end{abstract}

Key words: Electrolyte mixtures, primitive model electrolyte, random porous material, Donnan exclusion coefficient, Replica Ornstein-Zernike integral equation, Monte Carlo simulation

PACS: 82.60.-s, 02.30.Rz, 61.20.-p

\section{Introduction}

Partitioning of electrolytes between porous materials, adsorbents, and the bulk solution is not only a matter of academic interest, but finds its practical application in many technological, industrial and biological processes (desalination of water, ion exchange, membrane equilibria etc.) [1]. In all these processes the selectivity of the adsorption of different kinds of ions is crucial: the concentration ratio of competing ions in the adsorbent is different from that in the bulk solution [2]. Apart from numerous experimental studies the phenomena have been extensively studied theoretically, for review see, for example, [3,4]. While most of the earlier theories are based on the empirical or semiempirical equations, the later theories have been developed that provide the correct description of the phenomena based on the physical chemistry of these systems [1]. One of the first theories of this kind is based on the classical Donnan equilibrium [5] where the rejection of an electrolyte from the adsorbent is measured in terms of the so-called Donnan exclusion coefficient, $\Gamma$, which can be for a certain ionic species A, for this purpose, defined as [6]:

$$
\Gamma_{\mathrm{A}}=\frac{c_{\mathrm{A}}^{\text {out }}-c_{\mathrm{A}}^{\text {in }}}{c_{\mathrm{A}}^{\text {out }}}
$$

where $c_{\mathrm{A}}$ is the concentration of the ionic species A, and upper indexes "out" and "in" apply to the bulk solution and adsorbent, respectively.

A more detailed model of electrolyte exclusion, in which the ion concentration profiles in the adsorbent are evaluated from the properties of ions and the adsorbent, is based on the PoissonBoltzmann (PB) equation $[7,8]$. In contrast to the previous theories, different activity coefficients inside and outside the adsorbent are taken into account [9]. Although the PB theory has successfully described various experimental results it contains several statistical-thermodynamical approximations that can lead to unphysical results in some cases. In the last decades, new class of theories

*Dedicated to the 100-th anniversary of Prof. M.M. Bogolyubov. 
appeared in which the disordered porous materials filled with fluid are treated as partly quenched systems in which some of the degrees of freedom are quenched and others are annealed. The systems differ from regular mixtures; the statistical-mechanical average which is needed to obtain the free energy describing the confined fluid, becomes a double ensemble average [10-17]. The thermodynamic and structural properties of these systems can be calculated using the computer simulations and/or the replica integral equation theories. This work presents the continuation of our previous studies of partly quenched systems containing charges [18-25]. The quenched "phase" (we shall call it the matrix) is some frozen (quenched) equilibrium distribution of a symmetric model $+1:-1$ electrolyte. Within such a matrix, a model mixture of two $+1:-1$ or $+1:-1$ and $+z:-1$ electrolytes can anneal (come into thermodynamic equilibrium with the surrounding bulk solution of the same chemical composition) [24]. We present the results for the thermodynamic properties (the excess internal energy, and the mean activity coefficient) of a model electrolyte mixture confined in matrices of different densities. We were mostly interested in what way the density of the matrix of random structure effects the confined electrolyte activities and therefore the Donnan exclusion coefficients. Furthermore, we investigated how the size and/or charge asymmetry effects the adsorption of ions from electrolyte mixtures. The results were compared with the Monte Carlo simulation results obtained in the grand canonical ensemble.

\section{The model and methods}

The model used here was similar to the one described in several previous papers $[19,21,22,24]$. The system studied consisted of two subsystems: the first, here called the matrix, was composed of the quenched, and the second of the annealed ions. The assumption is that the matrix does not respond to the presence of the annealed fluid. The modeled system was considered at a McMillanMayer level of description; the solvent was treated as a dielectric continuum with the dielectric constant of pure water under conditions of study. We use the notation as it has already become traditional in describing such systems: the superscripts 0 and 1 correspond to the matrix and the annealed fluid species, respectively.

The matrix represented as an electroneutral system of positively and negatively charged hard spheres of equal sizes $\left(\sigma_{+}^{0}=\sigma_{-}^{0}=4.25 \AA\right)$ is assumed to be formed by a rapid quench of a model $+1:-1$ electrolyte at a certain temperature $T_{0}$. It is therefore assumed that the structure of the matrix corresponds to an equilibrium state of an ionic fluid of concentration $c_{0}$ at $T_{0}$, governed by the interaction potential between pair of particles:

$$
\frac{U_{i j}^{m n}(r)}{k_{\mathrm{B}} T}= \begin{cases}\infty, & r<\left(\sigma_{i}^{m}+\sigma_{j}^{n}\right) / 2, \\ z_{i}^{m} z_{j}^{n} \lambda_{\mathrm{B}} \cdot \frac{1}{r}, & r \geqslant\left(\sigma_{i}^{m}+\sigma_{j}^{n}\right) / 2,\end{cases}
$$

where $\lambda_{\mathrm{B}}$ is the Bjerrum length of the matrix $(m=0, n=0): \lambda_{\mathrm{B}}=\lambda_{\mathrm{B}, 0}=e_{0}^{2} /\left(4 \pi \epsilon_{0} \epsilon k_{\mathrm{B}} T_{0}\right) . \epsilon_{0}$ is the permittivity of the vacuum, $\epsilon$ is the relative permittivity of the solvent in which the matrix was equilibrated at temperature $T=T_{0}$, and $z_{i}$ is the ion charge. Finally, $r$ is the distance between centers of charges $i$ and $j$.

The annealed subsystem was modeled as a mixture of two $+1:-1$ or $+1:-1$ and $+z:-1$ electrolytes with a common anion. The potential function between two annealed ions $(m=n=1)$ as well as between a quenched and annealed ion $(m=1, n=0$ or $m=0, n=1)$ is of the same form as given by equation 2 , but with Bjerrum length being $\lambda_{\mathrm{B}}=\lambda_{\mathrm{B}, 1}=e_{0}^{2} /\left(4 \pi \epsilon_{0} \epsilon_{1} k_{\mathrm{B}} T_{1}\right)$. In general, the conditions of matrix preparation, $T_{0}, \epsilon$, can be different from the conditions of observation, given by $T_{1}$ and $\epsilon_{1}$. For simplicity, the temperature of observation was in this study assumed to be the same as the temperature of the quench, $T_{1}=T_{0}=T=298.15 \mathrm{~K}$, and $\lambda_{\mathrm{B}, 0}=\lambda_{\mathrm{B}, 1}=\lambda_{\mathrm{B}}=7.14 \AA$.

\subsection{The Replica Ornstein-Zernike theory}

The derivation of the replica Ornstein-Zernike (ROZ) equations for a single electrolyte adsorption was in detail described elsewhere (see [22]) and will not be repeated here. In the case of adsorption of an electrolyte mixture the general form of the equations in a matrix form remains 
the same. The distribution of matrix particles obtained in terms of the pair correlation functions follows from the integral equation

$$
\mathbf{H}^{00}-\mathbf{C}^{00}=\mathbf{C}^{00} \otimes \boldsymbol{\rho}^{0} \mathbf{H}^{00},
$$

where $\rho^{0}$ is a $2 \times 2$ diagonal matrix with diagonal elements $\rho_{+}^{0}=\rho_{-}^{0}$, and the symbol $\otimes$ denotes convolution. The correlation functions $\mathbf{H}$ and $\mathbf{C}$ are $2 \times 2$ symmetric matrices with the elements $f_{--}^{00}(r)=f_{++}^{00}(r) ; f_{+-}^{00}(r)=f_{-+}^{00}(r)$, where $f$ stands for $h$ or $c, h=g-1$ being the total, and $c$ being the direct correlation function [22].

The ROZ equations for the fluid-matrix and the fluid-fluid correlations read [22]:

$$
\begin{aligned}
& \mathbf{H}^{10}-\mathbf{C}^{10}=\mathbf{C}^{10} \otimes \boldsymbol{\rho}^{0} \mathbf{H}^{00}+\mathbf{C}^{11} \otimes \boldsymbol{\rho}^{1} \mathbf{H}^{10}-\mathbf{C}^{12} \otimes \boldsymbol{\rho}^{1} \mathbf{H}^{10}, \\
& \mathbf{H}^{11}-\mathbf{C}^{11}=\mathbf{C}^{10} \otimes \boldsymbol{\rho}^{0} \mathbf{H}^{01}+\mathbf{C}^{11} \otimes \boldsymbol{\rho}^{1} \mathbf{H}^{11}-\mathbf{C}^{12} \otimes \boldsymbol{\rho}^{1} \mathbf{H}^{21}, \\
& \mathbf{H}^{12}-\mathbf{C}^{12}=\mathbf{C}^{10} \otimes \boldsymbol{\rho}^{0} \mathbf{H}^{01}+\mathbf{C}^{11} \otimes \boldsymbol{\rho}^{1} \mathbf{H}^{12}+\mathbf{C}^{12} \otimes \boldsymbol{\rho}^{1} \mathbf{H}^{11}-2 \mathbf{C}^{12} \otimes \boldsymbol{\rho}^{1} \mathbf{H}^{21} .
\end{aligned}
$$

Here $\mathbf{C}^{12}$ and $\mathbf{H}^{12}$ are the matrices containing the blocking parts of the relevant distribution functions. $\rho^{1}$ is a $3 \times 3$ diagonal matrix with diagonal elements $\rho_{+, \mathrm{A}}^{1}=\rho_{\mathrm{A}}^{1}, \rho_{+, \mathrm{B}}^{1}=\rho_{\mathrm{B}}^{1}$, and $\rho_{-}^{1}$. The correlation functions $\mathbf{H}$ and $\mathbf{C}$ are also $3 \times 3$ matrices. For clarity, the elements of the first of the above equation 4 are in $k$-space given below:

$$
\begin{aligned}
& {\left[\begin{array}{ccc}
h_{\mathrm{A}, \mathrm{A}}^{11} & h_{\mathrm{A}, \mathrm{B}}^{11} & h_{\mathrm{A},-}^{11} \\
h_{\mathrm{B}, \mathrm{A}}^{11} & h_{\mathrm{B}, \mathrm{B}}^{11} & h_{\mathrm{B},-}^{11} \\
h_{-, \mathrm{A}}^{11} & h_{-, \mathrm{B}}^{11} & h_{-,-}^{11}
\end{array}\right]=\left[\begin{array}{ccc}
c_{\mathrm{A}, \mathrm{A}}^{11} & c_{\mathrm{A}, \mathrm{B}}^{11} & c_{\mathrm{A},-}^{11} \\
c_{\mathrm{B}, \mathrm{A}}^{11} & c_{\mathrm{B}, \mathrm{B}}^{11} & c_{\mathrm{B},-}^{11} \\
c_{-, \mathrm{A}}^{11} & c_{-, \mathrm{B}}^{11} & c_{-,-}^{11}
\end{array}\right]} \\
& +\left[\begin{array}{ccc}
c_{\mathrm{A},+}^{10} & c_{\mathrm{A},-}^{10} & 0 \\
c_{\mathrm{B},+}^{10} & c_{\mathrm{B},-}^{10} & 0 \\
c_{-,+}^{10} & c_{-,-}^{10} & 0
\end{array}\right]\left[\begin{array}{ccc}
\rho_{+}^{0} & 0 & 0 \\
0 & \rho_{-}^{0} & 0 \\
0 & 0 & 0
\end{array}\right]\left[\begin{array}{ccc}
h_{+, \mathrm{A}}^{01} & h_{+, \mathrm{B}}^{01} & h_{+,-}^{01} \\
h_{-, \mathrm{A}}^{01} & h_{-, \mathrm{B}}^{011} & h_{-,-}^{01} \\
0 & 0 & 0
\end{array}\right] \\
& +\left[\begin{array}{ccc}
c_{\mathrm{A}, \mathrm{A}}^{11} & c_{\mathrm{A}, \mathrm{B}}^{11} & c_{\mathrm{A},-}^{11} \\
c_{\mathrm{B}, \mathrm{A}}^{11} & c_{\mathrm{B}, \mathrm{B}}^{11} & c_{\mathrm{B},-}^{11} \\
c_{-, \mathrm{A}}^{11} & c_{-, \mathrm{B}}^{11} & c_{-,-}^{11}
\end{array}\right]\left[\begin{array}{ccc}
\rho_{\mathrm{A}}^{1} & 0 & 0 \\
0 & \rho_{\mathrm{B}}^{1} & 0 \\
0 & 0 & \rho_{-}^{1}
\end{array}\right]\left[\begin{array}{ccc}
h_{\mathrm{A}, \mathrm{A}}^{11} & h_{\mathrm{A}, \mathrm{B}}^{11} & h_{\mathrm{A},-}^{11} \\
h_{\mathrm{B}, \mathrm{A}}^{11} & h_{\mathrm{B}, \mathrm{B}}^{11} & h_{\mathrm{B},-}^{11} \\
h_{-, \mathrm{A}}^{11} & h_{-, \mathrm{B}}^{11} & h_{-,-}^{11}
\end{array}\right] \\
& -\left[\begin{array}{ccc}
h_{\mathrm{A}, \mathrm{A}}^{12} & h_{\mathrm{A}, \mathrm{B}}^{12} & h_{\mathrm{A}}^{12}- \\
h_{\mathrm{B}, \mathrm{A}}^{12} & h_{\mathrm{B}, \mathrm{B}}^{12} & h_{\mathrm{B},-}^{12} \\
h_{-, \mathrm{A}}^{12} & h_{-, \mathrm{B}}^{12} & h_{-,-}^{12}
\end{array}\right]\left[\begin{array}{ccc}
\rho_{\mathrm{A}}^{1} & 0 & 0 \\
0 & \rho_{\mathrm{B}}^{1} & 0 \\
0 & 0 & \rho_{-}^{1}
\end{array}\right]\left[\begin{array}{ccc}
h_{\mathrm{A}}^{21} & h_{\mathrm{A}, \mathrm{B}}^{21} & h_{\mathrm{A},-}^{21} \\
h_{\mathrm{B}, \mathrm{A}}^{21} & h_{\mathrm{B}, \mathrm{B}}^{21} & h_{\mathrm{B},-}^{21} \\
h_{-, \mathrm{A}}^{21} & h_{-, \mathrm{B}}^{21} & h_{-,-}^{21}
\end{array}\right] .
\end{aligned}
$$

Indexes $\mathrm{A}$ and $\mathrm{B}$ denote different cationic species of the annealed electrolyte mixture.

The integral equations written above can only be solved with the help of additional approximations, i. e. the so-called closure conditions. In this, as well as in many previous studies, we apply the HNC closure condition in the form:

$$
\mathbf{C}^{m n}(r)=e^{\left[-\beta \mathbf{U}^{m n}(r)+\Gamma^{m n}(r)\right]}-1-\Gamma^{m n}(r), \quad \mathbf{C}^{12}(r)=e^{\Gamma^{12}(r)}-1-\Gamma^{12}(r) .
$$

In this equation $\Gamma^{m n}=\mathbf{H}^{m n}-\mathbf{C}^{m n}$, and the superscripts $m, n$ assume values 0 and 1 . Further, $\mathbf{U}^{m n}$ are the matrices of interparticle pair potentials given by equation 2 and $\beta=1 /\left(k_{\mathrm{B}} T\right)$, where $k_{\mathrm{B}}$ is the Boltzmann constant.

The set of equations 4 and 6 must first be re-normalized before it can be solved numerically. The renormalization was carried out following the procedure described in $[19,20]$. The form of the renormalized functions remains the same as in the case of single electrolyte adsorption [20], except that $\kappa_{1}^{2}=4 \pi \sum \rho_{i}^{1}\left(z_{i}^{1}\right)^{2} \lambda_{\mathrm{B}, 1}$ contains the sum over all (three) fluid species. A direct iteration on a grid of 16,384 points with $\Delta r=0.05 \AA$ was used to solve the set of integral equations with the related closure conditions given above.

\subsubsection{Thermodynamic properties}

The excess internal energy of a charged fluid inside a charged matrix was calculated from equation $7[26]$ :

$$
\beta E^{\mathrm{ex}} / N_{1}=\frac{1}{2} \sum_{i=\mathrm{A}, \mathrm{B},-} \sum_{j=\mathrm{A}, \mathrm{B},-} x_{i}^{1} \rho_{j}^{1} \int \mathrm{d} \mathbf{r} g_{i j}^{11}(r) U_{i j}^{11}(r)+\sum_{i=\mathrm{A}, \mathrm{B},-} \sum_{j=+,-} x_{i}^{1} \rho_{j}^{0} \int \mathrm{d} \mathbf{r} g_{i j}^{10}(r) U_{i j}^{10}(r),
$$


where $x_{i}^{1}=\rho_{i}^{1} /\left(\rho_{A}^{1}+\rho_{\mathrm{B}}^{1}+\rho_{-}^{1}\right)$. Another thermodynamic property of special interest for this study is the excess chemical potential, $\mu_{i, 1}^{\text {ex }}=\ln \gamma_{i}^{1}$, of the adsorbed fluid. The equation has been derived for the single electrolyte in the adsorbent within ROZ/HNC approximation [22]. For the electrolyte mixture the equation reads:

$$
\begin{aligned}
\ln \gamma_{i}^{1}= & -\sum_{j=+,-} \rho_{j}^{0} \mathbf{c}_{(\mathbf{s}) \mathbf{i j}}^{\mathbf{1 0}}(\mathbf{0})-\sum_{j=\mathrm{A}, \mathrm{B},-} \rho_{j}^{1}\left[\mathbf{c}_{(\mathbf{s}) \mathbf{i j}}^{\mathbf{1 1}}(\mathbf{0})-\mathbf{c}_{(\mathbf{s}) \mathbf{i j}}^{\mathbf{1 2}}(\mathbf{0})\right]+0.5 \sum_{j=+,-} \rho_{j}^{0} \int \mathrm{d} \mathbf{r} h_{i j}^{10}\left(h_{i j}^{10}-c_{i j}^{10}\right) \\
& +0.5 \sum_{j=\mathrm{A}, \mathrm{B},-} \rho_{j}^{1} \int \mathrm{d} \mathbf{r}\left[h_{i j}^{11}\left(h_{i j}^{11}-c_{i j}^{11}\right)-h_{i j}^{12}\left(h_{i j}^{12}-c_{i j}^{12}\right)\right]
\end{aligned}
$$

where $\mathbf{c}_{(\mathbf{s}) \mathbf{i j}}^{\mathbf{1 0}}(\mathbf{0})$ denotes the Fourier transform of the direct correlation function at $k=0$.

\subsection{The Grand Canonical Monte Carlo simulation}

The matrix configuration was obtained using the canonical Monte Carlo simulation. After the equilibration, the matrix ions were frozen in their positions. The annealed electrolyte ions were then distributed within the matrix and the system was studied by the grand canonical Monte Carlo (GCMC) method. The methodology of the method is well established and extensively described in several previous papers and therefore is not repeated here $[6,23,24,27,28]$. The details of the simulations are: the number of matrix particles was 1000 and the average number of a fluid cation species distributed within the matrix varied from 50 to 400. The ions within the matrix were first equilibrated over at least $10^{6}$ GCMC steps. After the equilibration, the production run of $2 \cdot 10^{8}$ attempted configurations was carried out to obtain the average concentration of the adsorbed electrolyte species.

The mean activity coefficients of the annealed electrolyte, $\gamma_{ \pm}^{1}$, were calculated from the equilibrium relation

$$
a_{ \pm}^{1}=\gamma_{ \pm}^{1} \cdot\left(\left(c_{+}^{1}\right)^{z_{+}}\left(c_{-}^{1}\right)^{z_{-}}\right)^{1 /\left(z_{+}+z_{-}\right)}=\left(a_{ \pm}^{\text {out }}\right)=\gamma_{ \pm}^{\text {out }} \cdot\left(\left(c_{+}^{\text {out }}\right)^{z_{+}}\left(c_{-}^{\text {out }}\right)^{z_{-}}\right)^{1 /\left(z_{+}+z_{-}\right)}
$$

where index + refers to one of the cation species, and out refers to the properties of the bulk electrolyte mixture. The activity coefficients of the bulk electrolyte mixture, $\gamma_{ \pm}^{\text {out }}$, were obtained using the hypernetted-chain (HNC) theory which has proved to be very successful in describing the properties of ionic fluids [24].

\section{Results and discussion}

\subsection{Test of the method}

The first step of this study was to test out the newly written ROZ equations in HNC approximation in order to describe the thermodynamic and structural properties of electrolyte mixtures adsorbed in electroneutral matrices. We compared the internal energy (equation 7) and excess chemical potential (equation 8) obtained within ROZ/HNC theory with the newly obtained results from GCMC simulations for two different mixtures of fluids: (i) $z_{\mathrm{A}}=z_{\mathrm{B}}=+1, \sigma_{\mathrm{A}}^{1}=5.04 \AA$ (the model for $\mathrm{H}^{+}$ion), $\sigma_{\mathrm{B}}^{1}=3.87 \AA$ (the model for $\mathrm{Na}^{+}$ion), and $\sigma_{-}^{1}=3.62 \AA$ (the model for $\mathrm{Cl}^{-}$ ion) $[29]$; and (ii) $z_{\mathrm{A}}=+1, z_{\mathrm{B}}=+2, \sigma_{\mathrm{A}}^{1}=5.04 \AA$ (the model for $\mathrm{H}^{+}$ion), $\sigma_{\mathrm{B}}^{1}=7.03 \AA$ (the model for $\mathrm{Ca}^{2+}$ ion), and $\sigma_{-}^{1}=3.62 \AA$ (the model for $\mathrm{Cl}^{-}$ion) [29]. In all cases $z_{-}^{1}=-1$. The results for thermodynamic properties are collected in table 1 , and the comparison between different pair distribution functions is for one case shown in figure 1.

Figure 1 shows an excellent agreement between fluid ion-ion and fluid ion-matrix pair distribution functions for the model (i), i. e. $\mathrm{HCl}+\mathrm{NaCl}: c_{0}=1.0 \mathrm{M}, c_{\mathrm{H}^{+}}^{1}=0.1797 \mathrm{M}$, and $c_{\mathrm{Na}^{+}}^{1}=0.1987$ M. The same agreement was obtained for other fluid/matrix concentrations, as well as for the model (ii), i. e. the mixture of $\mathrm{HCl}$ and $\mathrm{CaCl}_{2}$. As a consequence, the results for the excess internal energy and the activity coefficients that are in the ROZ/HNC theory calculated from the pair distribution functions (equation 7 and 8) and are collected in table 1 also show a reasonably good 
agreement with the GCMC simulation, as was previously observed for a single electrolyte annealed fluid $[21,22]$.
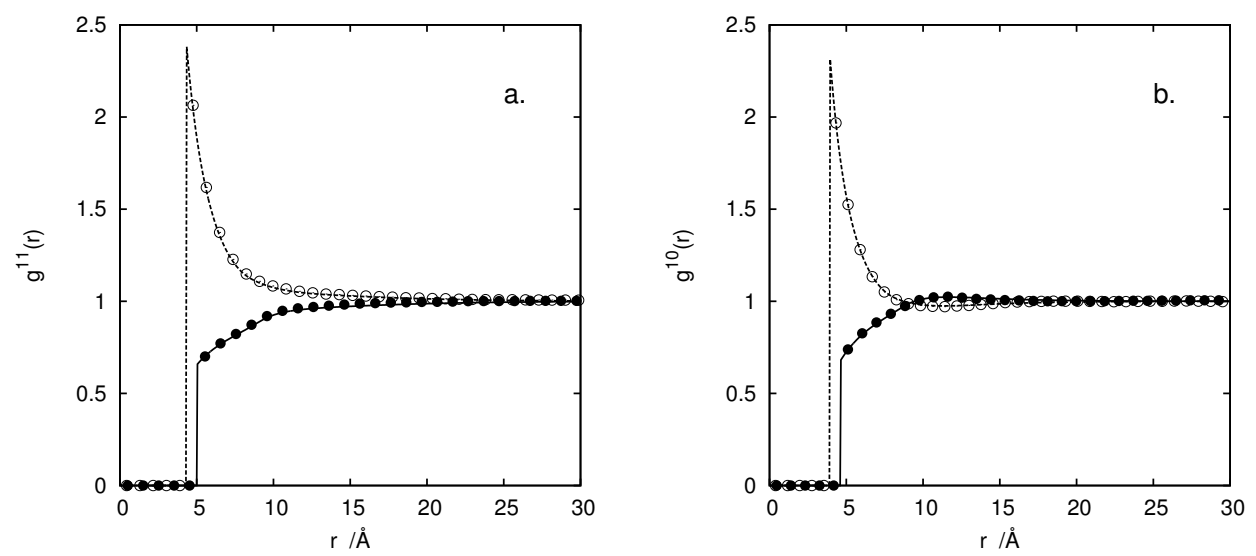

Figure 1. (a) Fluid-fluid pair distribution function $g^{11}(r)$ and (b) fluid-matrix pair distribution function $g^{10}(r)$ for model (i), i. e. $\mathrm{HCl}+\mathrm{NaCl}$. The lines show the ROZ/HNC results, and the symbol results from the GCMC simulations. $c_{0}=1.0 \mathrm{M}, c_{\mathrm{A}}=0.1797 \mathrm{M}, c_{\mathrm{B}}=0.1987 \mathrm{M}$.

Table 1. The excess internal energy per annealed fluid particle, $-E^{\mathrm{ex}} / N_{1} k_{\mathrm{B}} T$, and the mean activity coefficient, $\gamma_{ \pm}$, as obtained from ROZ/HNC theory, and GCMC simulation. The parameters of the two models are given in the text.

\begin{tabular}{|c|c|c|c|c|c|c|c|}
\hline \multirow[b]{2}{*}{$c_{\mathrm{HCl}}$} & \multirow[b]{2}{*}{$c_{\mathrm{NaCl}}$} & \multicolumn{2}{|c|}{$-E / N_{1} k_{\mathrm{B}} T$} & \multicolumn{2}{|c|}{$\gamma_{ \pm}^{\mathrm{HCT}}$} & \multicolumn{2}{|c|}{$\gamma_{ \pm}^{\mathrm{NaCT}}$} \\
\hline & & GCMC & $\mathrm{ROZ}$ & GCMC & ROZ & GCMC & $\mathrm{ROZ}$ \\
\hline 0.0712 & 0.3171 & $0.77(7)$ & 0.791 & $1.07(0)$ & 1.061 & $0.90(9)$ & 0.907 \\
\hline 0.1435 & 0.2384 & $0.77(0)$ & 0.783 & $1.07(5)$ & 1.070 & $0.91(5)$ & 0.914 \\
\hline 0.2161 & 0.1593 & $0.76(2)$ & 0.774 & $1.08(2)$ & 1.078 & $0.92(3)$ & 0.920 \\
\hline \multirow[t]{2}{*}{0.2892} & 0.0796 & $0.75(3)$ & 0.765 & $1.09(0)$ & 1.087 & $0.93(2)$ & 0.927 \\
\hline & & \multicolumn{2}{|c|}{$-E / N_{1} k_{\mathrm{B}} T$} & \multicolumn{2}{|c|}{$\gamma_{ \pm}^{\mathrm{HCl}}$} & \multicolumn{2}{|c|}{$\gamma_{ \pm}^{\mathrm{CaCl}_{2}}$} \\
\hline$c_{\mathrm{HCl}}$ & $c_{\mathrm{CaCl}_{2}}$ & GCMC & $\mathrm{ROZ}$ & GCMC & $\mathrm{ROZ}$ & GCMC & $\mathrm{ROZ}$ \\
\hline 0.0278 & 0.1087 & $1.29(5)$ & 1.248 & $1.03(6)$ & 1.027 & $0.75(8)$ & 0.775 \\
\hline 0.0663 & 0.0961 & $1.19(2)$ & 1.150 & $1.03(3)$ & 1.035 & $0.76(6)$ & 0.782 \\
\hline 0.1220 & 0.0781 & $1.07(5)$ & 1.096 & $1.04(0)$ & 1.040 & $0.77(7)$ & 0.787 \\
\hline 0.2095 & 0.0500 & $0.93(9)$ & 0.908 & $1.05(6)$ & 1.064 & $0.79(3)$ & 0.809 \\
\hline
\end{tabular}

\subsection{Donnan exclusion coefficients}

Since, in general, the ions differ in size and charge we proceed with a systematic study of each effect separately. First we studied the Donnan exclusion coefficient, $\Gamma$, of a cation $B$ of different sizes where all the other ions in an annealed electrolyte mixture were of the same size: $z_{\mathrm{A}}=z_{\mathrm{B}}=+1$, $z_{-}^{1}=-1, \sigma_{\mathrm{A}}^{1}=\sigma_{-}^{1}=4.25 \AA$ and $\sigma_{\mathrm{B}}^{1}=4.25,5.00,6.00$, or $7.00 \AA$. The matrix was as described above. The results for different mixture compositions $\left(c_{0}=1.0 \mathrm{M}, I^{\mathrm{in}}=0.5 \sum_{j=\mathrm{A}, \mathrm{B},-} c_{j}^{1}\left(z_{j}^{1}\right)^{2}=0.5\right.$ $\mathrm{M})$ are as a function of $X_{\mathrm{A},-}^{\text {in }}=c_{\mathrm{A},-}^{\text {in }} /\left(c_{\mathrm{A},-}^{\text {in }}+c_{\mathrm{B},-}^{\text {in }}\right)$ shown in figure $2 \mathrm{a}$. As the size of the ion increases, $\Gamma$ increases to more positive values, which means that the big ion gets excluded from the matrix to a larger extent. As previously established, this is a results of the excluded volume effect.

In figure $2 \mathrm{~b}$ we show $\Gamma$ of cation $\mathrm{B}$, where $\sigma_{\mathrm{B}}^{1}=4.25 \AA$ but its charge, $z_{\mathrm{B}}$ varies from +1 to +4 . Again, $c_{0}=1.0 \mathrm{M}$, and $I^{\text {in }}=0.5 \mathrm{M}$. With the increasing charge of the ion (increasing ion charge density), the Donnan exclusion coefficient $\Gamma$ decreases and finally (for $z_{\mathrm{B}}=+4$ ) becomes negative, showing the actual sorption of the component: the concentration of the ion $\mathrm{B}$ is higher in the matrix than in the bulk of the same chemical potential. This can be explained with the 
stronger electrostatic attraction between annealed ions with high charge density and oppositely charged matrix ions.
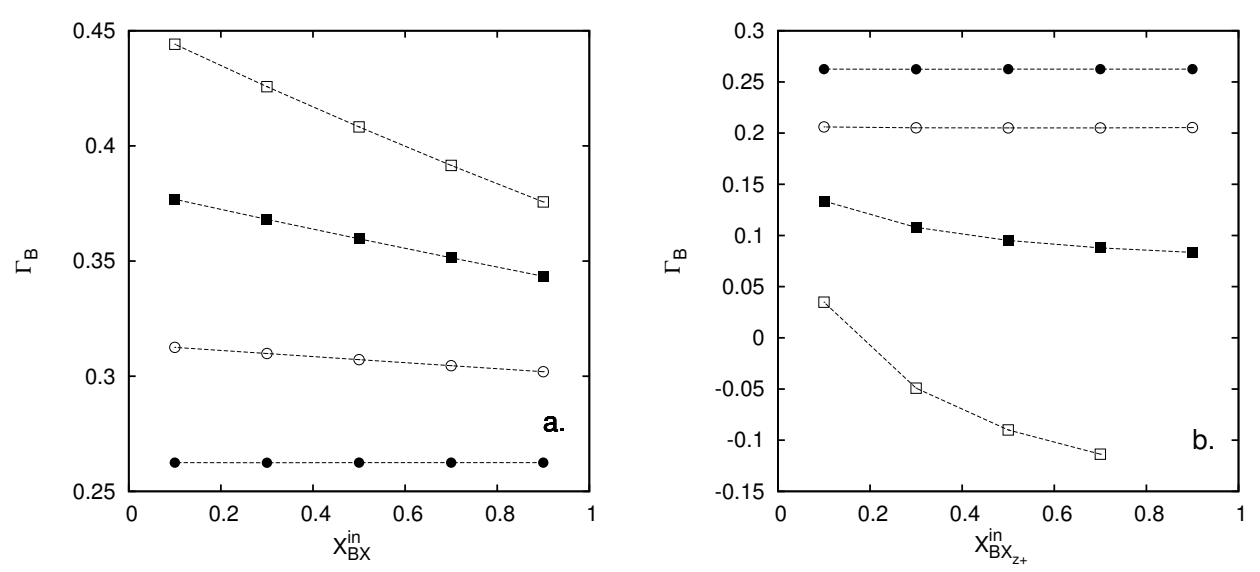

Figure 2. (a) Donnan exclusion coefficient $\Gamma$ for different sizes of cation $\mathrm{B}, \sigma_{\mathrm{B}}^{1}: 4.25 \AA$ (full circles), $5.0 \AA$ (empty circles), $6.0 \AA$ (full squares), $7.0 \AA$ (empty squares). (b) $\Gamma$ for different charges of cation $\mathrm{B}, z_{\mathrm{B}}:+1$ (full circles), +2 (empty circles), +3 (full squares), and +4 (empty squares). Other parameters are described in the text. All results were obtained using ROZ/HNC theory.
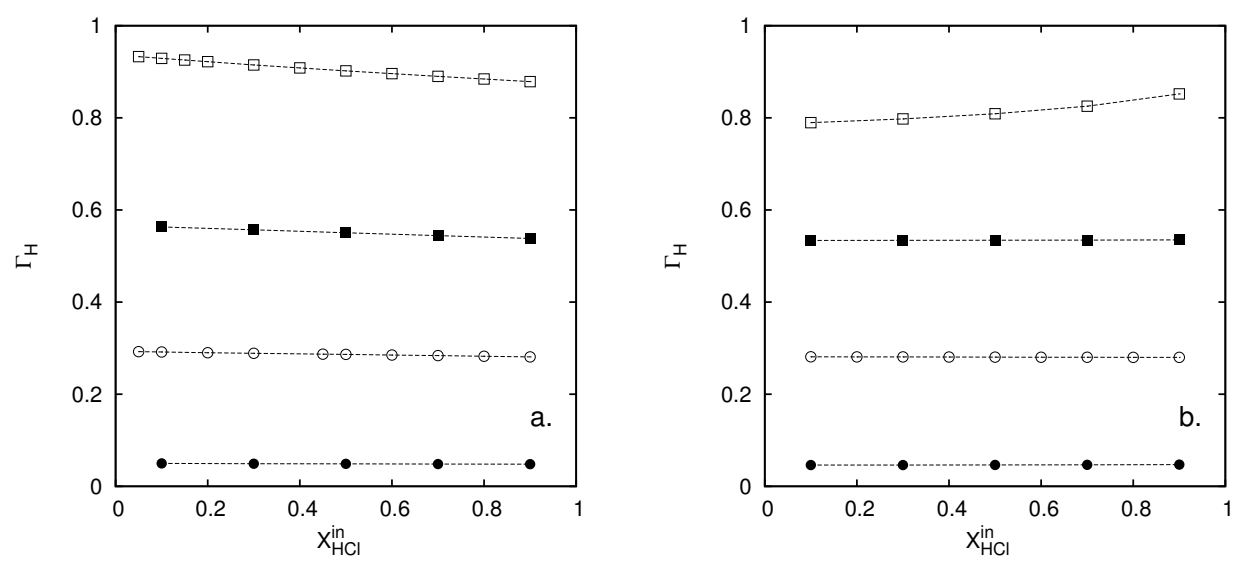

Figure 3. Donnan exclusion coefficient $\Gamma$ for $\mathrm{H}^{+}$cation in (a) model (i), i. e. $\mathrm{HCl}+\mathrm{NaCl}$, and (b) model (ii), i. e. $\mathrm{HCl}+\mathrm{CaCl}_{2} \cdot I^{\text {in }}=0.5 \mathrm{M}$, and $c_{0}=0.2 \mathrm{M}$ (full circles), $1.0 \mathrm{M}$ (empty circles), 2.0 M (full squares), and 5.0 M (empty squares). All the results were obtained using ROZ/HNC theory.

Both effects, excluding volume and electrostatics, result from the interaction with matrix particles. It is therefore to be expected that the matrix concentration importantly effects the exclusion coefficients of ions. In figure 3 we show the Donnan exclusion coefficient for $\mathrm{H}^{+}$ion in models (i), i. e. $\mathrm{HCl}+\mathrm{NaCl}$ (figure $3 \mathrm{a}$ ), and (ii), i. e. $\mathrm{HCl}+\mathrm{CaCl}_{2}$ (figure $3 \mathrm{~b}$ ); $I^{\text {in }}=0.5 \mathrm{M}$, and $c_{0}$ varies from $0.2 \mathrm{M}$ to $5.0 \mathrm{M}$.

As the matrix concentration increases the Donnan exclusion coefficient increases to more positive values suggesting that the volume exclusion effect prevails over the electrostatic attraction. 


\subsection{Preferential adsorption}

For practical applications of electrolyte mixture adsorption, such as water softening and water deionization, the mixture composition in the adsorbent versus the mixture composition in the bulk is of particular interest. Figure 4 shows such ion-exchange isotherms obtained using ROZ/HNC for models (i), i. e. $\mathrm{HCl}+\mathrm{NaCl}$, and (ii), i. e. $\mathrm{HCl}+\mathrm{CaCl}_{2}$, for different matrix concentrations.
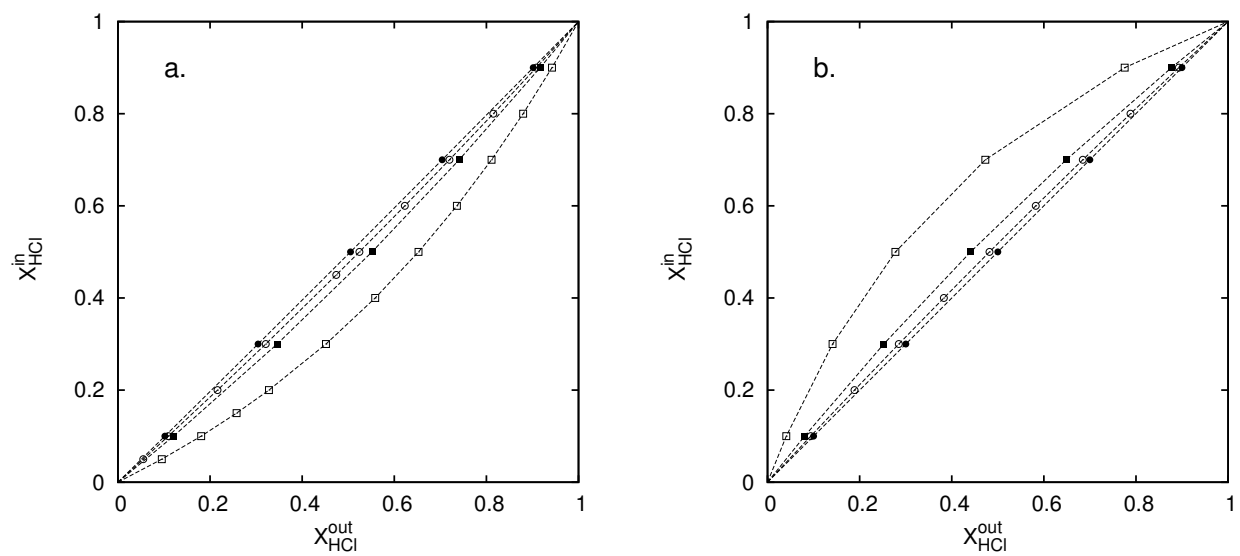

Figure 4. Ion-exchange isotherms $\left(X_{\mathrm{HCl}}^{\mathrm{in}}\right.$ as a function of $\left.X_{\mathrm{HCl}}^{\text {out }}\right)$ for (a) model (i), i. e. $\mathrm{HCl}+$ $\mathrm{NaCl}$, and (b) model (ii), i. e. $\mathrm{HCl}+\mathrm{CaCl}_{2} \cdot I^{\text {in }}=0.5 \mathrm{M}$, and $c_{0}=0.2 \mathrm{M}$ (full circles), $1.0 \mathrm{M}$ (empty circles), 2.0 M (full squares), and 5.0 M (empty squares). All results were obtained using ROZ/HNC theory.

For the lowest matrix concentration studied here $\left(c_{0}=0.2 \mathrm{M}\right)$ almost no preferential adsorption is observed $\left(X_{\mathrm{HCl}}^{\mathrm{in}} \approx X_{\mathrm{HCl}}^{\text {out }}\right)$. At higher matrix concentrations, the larger cation $\left(\mathrm{H}^{+}\right.$in model (i) and $\mathrm{Ca}^{2+}$ in model (ii)) gets partly excluded from the matrix. Note that the charge densities of the model $\mathrm{H}^{+}$and $\mathrm{Ca}^{2+}$ ions are approximately the same and the partition of the mixture components is, therefore, determined by the excluded volume effect. As expected, the phenomenon is more pronounced at higher matrix concentrations.

\section{Conclusions}

The ROZ/HNC equations for an annealed electrolyte mixture in an electroneutral matrix with charges were tested against GCMC simulation results. Good agreement was obtained for structural and thermodynamic properties, such as excess internal energy, and excess chemical potential. The theory was then used to study the excluded volume and electrostatic effect in the process of the adsorption of electrolyte mixtures with a common anion. The results show that in most cases studied here the ions get excluded from the adsorbent, in other words, the excluded volume effect prevails. Only in the case of highly charged annealed ions, the sorption occurs; the electrolyte gets sucked into the adsorbent. A more systematic study of the matrix structure (quenching) and charge density on the adsorption isotherms will be a subject of future work. We will pay special attention to the charged matrices that will be used as a model to study the ion exchange phenomena and will enable a direct comparison with experiments.

\section{Acknowledgements}

M. L. and B. H.-L. appreciate the financial support of the Slovenian Research Agency through grant P1-0201, and G. T. through grant PR-02485. 


\title{
References
}

1. Vlachy V., Haymet A.D.J., Aust. J. Chem., 1990, 43, 1961-1982.

2. Helfferich F. Ion Exchange. McGraw Hill, New York, 1962.

3. Rosinberg M.L. - In: New Approaches to Problems in Liquid State Theory, eds. Caccamo C., Hansen J.P., Stell G. Kluwer, Dordrecht, 1999, p. 245-278.

4. Pizio O. - In: Computational Methods in Surface and Colloid Chemistry, ed. Borowko M. Marcel Dekker, New York, 2000, p. 293-345.

5. Donnan F., Z. Elektrochem., 1911, 17, 572-581.

6. Jamnik B., Vlachy V., J. Am. Chem. Soc., 1995, 117, 8010-8016.

7. Lozada-Cassou M. - In: Fundamentals of Inhomogeneous Fluids, ed. D. Henderson. Marcel Dekker, New York, 1992, p. 303-323.

8. Dolar D., Vlachy V., Vestn. Slov. Kem. Drus., 1981, 28, 327-338.

9. Dresner L., Kraus K.A., J. Phys. Chem., 1963, 67, 990-996.

10. Madden W.G., Glandt E.G., J. Stat. Phys., 1988, 51, 537-558.

11. Madden W.G., J. Chem. Phys., 1992, 96, 5422-5432.

12. Given J.A., Stell G., J. Chem. Phys., 1992, 97, 4573-4574.

13. Given J.A., Stell G., Physica A, 1994, 102, 495-510.

14. Given J.A., J. Chem. Phys., 1995, 102, 2934-2945.

15. Tatlipinar H., Pastore G., Tosi M.P., Phil. Mag. Lett., 1993, 68, 357-361.

16. Rosinberg M.L., Tarjus G., Stell G., J. Chem. Phys., 1994, 100, 5172-5177.

17. Pizio O., Sokolowski S., J. Phys. Studies., 1998, 2, 296-321.

18. Hribar B., Pizio O., Trokhymchuk A., Vlachy V., J. Chem. Phys., 1997, 107, 6335-6341.

19. Hribar B., Pizio O., Trokhymchuk A., Vlachy V., J. Chem. Phys., 1998, 109, 2480-2489.

20. Hribar B., Vlachy V., Trokhymchuk A., Pizio O., J. Phys. Chem. B, 1999, 103, 5361-5369.

21. Hribar B., Vlachy V., Pizio O., J. Phys. Chem. B, 2001, 105, 4727-4734.

22. Hribar B., Vlachy V., Pizio O., Molec. Phys., 2002, 100, 3093-3103.

23. Lukšič M., Hribar-Lee B., Vlachy V., J. Phys. Chem. B, 2007, 111, 5966-5975.

24. Trefalt G., Hribar-Lee B., Acta Chim. Slov., 2007, 54, 503-508.

25. Jardat M., Hribar-Lee B., Vlachy V., Phys. Chem. Chem. Phys., 2008, 10, 449-457.

26. Kierlik E., Rosinberg M.L., Tarjus G., Monson P.A., J. Chem. Phys., 1997, 106, 264-279.

27. Allen M.P., Tildesley D.J. Computer Simulation of Liquids. Clarendon Press, Oxford, 2006.

28. Duh D.M., Haymet A.D.J., J. Chem. Phys., 1992, 97, 7716-7729.

29. Simonin J.P., Bernard O., Blum L., J. Phys. Chem. B, 1998, 102, 4411-4417.

\section{Застосування граничних рівнянь Орнштейна-Церніке при вивченні адсорбції сумішей електролітів у невпорядкованих матрицях заряджених частинок}

\author{
М. Лукшіч ${ }^{1}$, Г. Трефальт², Б. Хрібар-Лі ${ }^{1}$ \\ 1 Факультет хімії та хімічних технологій, Університет Любляни, Любляна, Словенія \\ 2 Інститут ім. Йожефа Стефана, вул. Ямова 39, SI-1000 Любляна, Словенія
}

Отримано 9 червня 2009 р., в остаточному вигляді - 19 червня 2009 р.

\begin{abstract}
Реплічне рівняння Орнштейна-Церніке (РОЦ) застосоване для вивчення адсорбції іонів із сумішей електролітів. Адсорбент розглядається у вигляді замороженої примітивної $+1:-1$ моделі розмірно симетричного електроліту, тоді як рухомі частинки - це іони, що відрізняються зарядом та/або розмірами. Дані, що отримані з рівняння РОЦ у гіперланцюжковому наближенні (ГЛН), порівняно з новими результатами Монте-Карло моделювання у великому канонічному ансамблі і виявлено хороше узгодження між обома методами. Теорію РОЦ/ГЛН далі було використано для вивчення коефіцієнтів виключення, в залежності від параметрів розмірної та/або зарядової асиметрій нерухомих іонів.
\end{abstract}

Ключові слова: суміші електролітів, примітивна модель електроліту, випадкові пористі матеріали, коефіцієнт виключення Доннана, реплічне інтегральне рівняння Орнштейна-Церніке, моделювання Монте-Карло

PACS: $82.60 .-s, 02.30 . R z, 61.20 .-p$ 